\title{
Fusion of CT and MR Liver Images Using Multiresolution Analysis Methods
}

\author{
Mücahit Cihan $^{1 *}$, Murat Ceylan ${ }^{2}$ \\ 1* Konya Technical University, Faculty of Engineering and Natural Sciences, Electrical and Electronics Engineering, Konya, Turkey (ORCID: 0000-0002-1426-319X), \\ mcihan@ktun.edu.tr \\ ${ }^{2}$ Konya Technical University, Faculty of Engineering and Natural Sciences, Electrical and Electronics Engineering, Konya, Turkey (ORCID: 0000-0001-6503-9668), \\ mceylan@ktun.edu.tr
}

( $2^{\text {nd }}$ International Conference on Computer, Electrical and Electronic Sciences ICCEES 2021 - 1-3 Eylül 2021)

(DOI: 10.31590/ejosat.1005858)

ATIF/REFERENCE: Cihan, M. \& Ceylan, M. (2021). Fusion of CT and MR Liver Images Using Multiresolution Analysis Methods. European Journal of Science and Technology, (30), 56-61.

\begin{abstract}
There are various medical imaging techniques such as Computed Tomography (CT) and Magnetic Resonance (MR) techniques. Both techniques give complex features of the region to be imaged. This study proposes an approach that uses Multiresolution Analysis (MRA) methods to fuse CT and MR liver images to obtain as detailed images as possible for medical diagnostic purposes. The transform coefficients are obtained by applying MRA methods to the images. Images are combined by applying 3 different fusion rules to these transform coefficients. Peak Signal to Noise Rate (PSNR), Structural Similarity Index Measure (SSIM) and Mean Square Error (MSE) values are calculated to evaluate the fused images. When comparing the methods, the best result was obtained using complex-valued curvelet transform.
\end{abstract}

Keywords: Image Fusion, Multiresolution Analysis Methods, CT, MR.

\section{Çoklu Çözünürlük Analiz Yöntemleri Kullanılarak BT ve MR Karaciğer Görüntülerinin Füzyonu}

$\ddot{\mathbf{O z}}$

Bilgisayarlı Tomografi (BT) ve Manyetik Rezonans (MR) teknikleri gibi çeşitli tıbbi görüntüleme teknikleri mevcuttur. Her iki teknik de görüntülenecek bölgenin kompleks özelliklerini vermektedir. Bu çalışma, tıbbi teşhis amacıyla mümkün olduğunca ayrıntılı görüntüler elde etmek için BT ve MR karaciğer görüntülerini birleştirmek için Çoklu Çözünürlük Analizi (ÇÇA) yöntemlerini kullanan bir yaklaşım önermektedir. Görüntülere ÇÇA yöntemleri uygulanarak dönüşüm katsayıları elde edilir. Bu dönüşüm katsayılarına 3 farklı füzyon kuralı uygulanarak görüntüler birleştirilir. Birleştirilmiş görüntüleri değerlendirmek için Tepe sinyal-gürültü oranı (PSNR), Yapısal benzerlik endeksi Ölçümü (SSIM) ve Ortalama Kare Hata (MSE) değerleri hesaplanmıştır. Kullanılan ÇÇA yöntemleri karşılaştırıldığında, en iyi sonuç kompleks-değerli curvelet dönüşümü kullanılarak elde edilmiştir.

Anahtar Kelimeler: Görüntü Füzyonu, Çoklu Çözünürlük Analiz Yöntemleri, BT, MR.

\footnotetext{
* Corresponding Author: mcihan@,ktun.edu.tr
} 


\section{Introduction}

Image fusion is the process of combining two images of the same scene to create a single image containing as much information as possible. Image fusion is important in many different image processing fields, such as satellite imaging, remote sensing, and medical imaging. The study in the field of image fusion evolved to serve the advancement in satellite imaging and was subsequently expanded into the field of medical imaging (Ali et al., 2008). In medical imaging, the images of different modalities can be combined to aid the diagnostic process. The purpose of image fusion is to reduce the amount of data, as well as to create new images that are more suitable for human/machine detection purposes and further image processing tasks such as segmentation, object detection or target recognition in applications like remote sensing and medical imaging (Ali et al., 2010).

Multiresolution Analysis (MRA) methods have become very popular especially with the development of wavelets. MRA methods that capture different features of images at various scales are widely used in image processing applications (Öztürk and Ceylan, 2015). Multiresolution is concerned with the display and analysis of images in different resolutions. Inconspicuous features at one level can be easily detected at another. Multiresolution analysis is based on Wavelet Transform (Morlet et al., 1982). Wavelet Transform (WT) was used in medical images for the first time in the studies of Mojsilovic et al. (1996). There are several image fusion studies done with different MRA methods. Ali et al. (2010), CT and MR medical images were combined using the curvelet transform. Image fusion was applied using the Ridgelet transform (Bhateja et al., 2015).

In this study, CT and MR images obtained from 46 patients were used for image fusion. Three different MRA methods were used for the fusion process. These methods are $2 \mathrm{~d}$-discrete wavelet transform (2D-DWT), ridgelet transform and curvelet transform. Three different fusion rules (mean, maximum and minimum) were determined for the study. Peak Signal to Noise Rate, Structural Similarity Index Measure and Mean Square Error values were obtained to evaluate the obtained fusion images. For both CT and MR images, the best result was achieved using complex-valued curvelet transform.

\section{Material and Method}

In this study, MRA techniques are given in Section 2.1. Image registration is included in Section 2.2. Image fusion and fusion rules are given in Section 2.3. Performance evaluation methods are given in Section 2.4.

\subsection{Multiresolution Analysis (MRA) Methods}

\subsubsection{Wavelet Transform (WT)}

Wavelet Transform is an effective tool used for image analysis methods. WT is a method that examines each component in a resolution suitable for its scale by dividing the data into different frequency components (Cihan and Ceylan, 2021). One of its biggest advantages is that it allows local analysis. In this way, large signals can be analyzed in a small area. Figure 1(a) shows the 2D-DWT analysis process using filter functions. Also, Figure 1(b) shows the first level decomposition process and the wavelet coefficients obtained as a result for 2D-DWT. As a result of this process, the approximation coefficients are obtained by applying a low-pass filter (L (n)), and by applying a high-pass filter $(\mathrm{H}(\mathrm{n}))$, the detail coefficients are obtained. LL includes the approximation coefficients, while LH, HL and $\mathrm{HH}$ include the detail coefficients. Higher level decomposition processes can be applied by using LL coefficients.

The wavelet function family is obtained by shifting and scaling the mother wavelet function. Equation 1 shows a wavelet formula derived from the mother wavelet. Parameter a is the scaling factor, parameter $b$ is the shifting factor. Here the scaling factor is a real number greater than zero and the shifting factor is a real number.

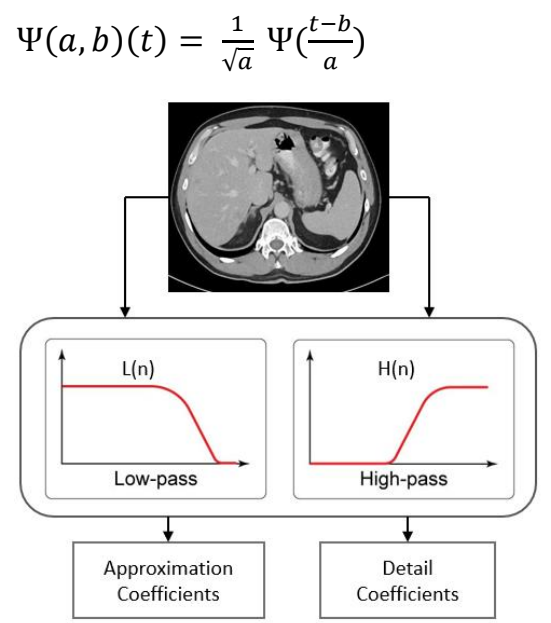

(a)

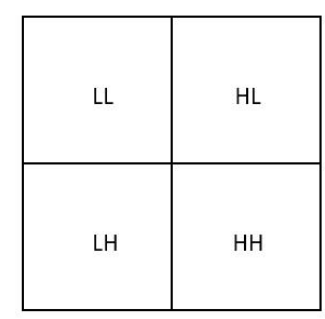

(b)
Figure 1. Applying WT to an image: (a) one-level twodimensional WT, (b) WT coefficient matrix obtained by decomposition level

\subsubsection{Ridgelet Transform}

Although Wavelet Transform is a successful method of capturing point singularities in one-dimensional particle smooth functions, it cannot efficiently represent objects with highly anisotropic elements such as linear or curvilinear structures (i.e., edges and corners). This is because wavelets are not geometric and cannot benefit from edge curve regularity (Candes and Donoho, 2004).

While applying ridgelet transform, which is a preferred method in image analysis studies, the ridgelet function (Equation 2 ) is used. The ridgelet function provides a versatile analysis along straight lines thanks to the angle parameter it contains. Ridgelet transform is implemented similarly to WT. The ridgelet transform coefficients of a 2D signal $f\left(x_{1}, x_{2}\right)$ are obtained from the product of the original signal and the ridgelet function (Equation 3). In Equation 3, $\Psi($. . represents 1D wavelet function so that $x=\left(x_{1} x_{2}\right) \in R^{2}$ condition is satisfied. In the same equation, $\theta(\theta \in[0,2 \pi))$ is the direction parameter (Öztürk et al., 2014).

$$
\begin{aligned}
& \Psi_{s, p, \theta}(x)=s^{-1 / 2} \Psi\left(\left(x_{1} \cos \theta+x_{2} \sin \theta-p\right) / s\right) \\
& R(s, p, \theta)=\int_{R^{2}} \Psi_{s, p, \theta}(x) f\left(x_{1}, x_{2}\right) d x_{1} d x_{2}
\end{aligned}
$$

Ridgelet transform is basically a radon transform; the radon transform is also based on the fourier transform. To obtain the radon transform coefficients of an image, first the $2 \mathrm{D}$ fourier transform of the image is taken and interpolated along straight lines to the obtained coefficients. When 1D inverse fourier is 
applied to the result of interpolation, radon coefficients are obtained. Radon transforms the curves contained in images into point discontinuities. The radon transform of an image $(f(x, y))$ can also be expressed as follows to show the $\delta$ Dirac distribution:

$P(r, \theta)=\int_{R^{2}} f(x, y) \delta(x \cos \theta+y \sin \theta-r) d x d y$

If $1 \mathrm{D} \mathrm{WT}$ is applied to the Radon coefficients, ridgelet transform coefficients are reached (Equation 4). The application of ridgelet transform depending on the fourier transform is given in Figure 2.

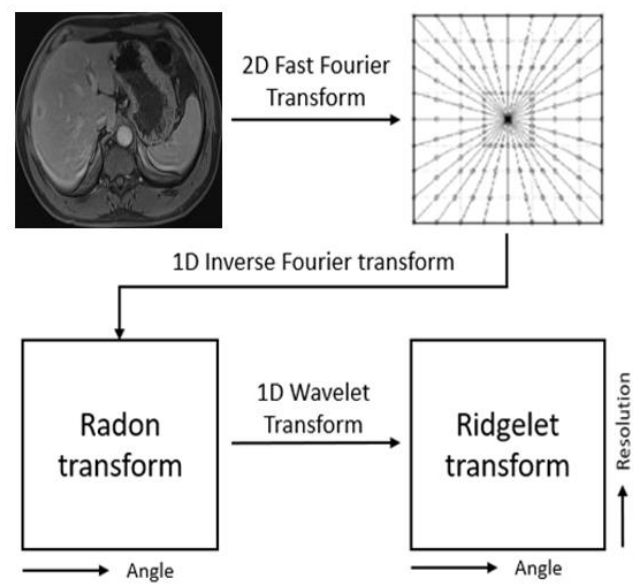

Figure 2. Scheme of Ridgelet Transform

\subsubsection{Curvelet Transform}

Edge structures on the image are curved rather than straight lines. Although ridgelet transform was a successful method for capturing regions containing edges and linear singularities, it was insufficient to capture regions containing curvilinear singularities. Curvelet Transform has been developed to solve this problem (Fadili and Starck, 2009).

The curvelet transform was first introduced by Candes and Donoho (1999) and revised in 2003. Curvelet transform is a high dimensional generalization of wavelet transform designed to represent images in different scales and directions (angles). It is seen as a multi-scale pyramid with frame elements indexed according to position, scale and direction parameters. Curvelet pyramid has a very high directional sensitivity and degree of anisotropy (Alzubi et al., 2011).

There are two types of curvelet transform, called first generation and second generation. Although the first-generation curvelet transform is used effectively to remove noise from images, it requires more processing time compared to the second generation. In addition, the numerical implementation of the firstgeneration curvelet transform is quite complex, and the secondgeneration curvelet transform can be applied in a shorter time, with less processing and in a simpler manner (Candes et al., 2006). In this study, we used the second-generation curvelet transform with real and complex values. The scheme of the second-generation curvelet transform is given in Figure 3.

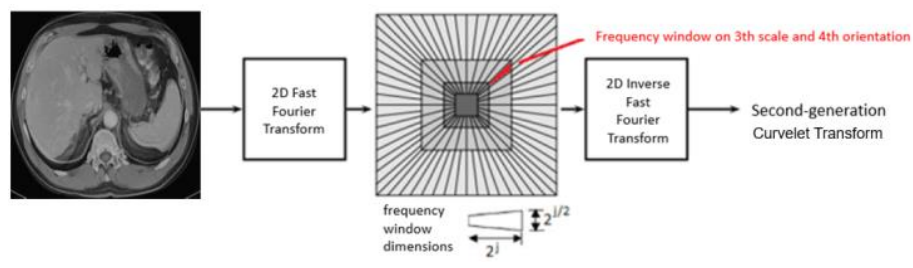

Figure 3. Scheme of Curvelet Transform

\subsection{Image Registration}

In order for the fusion process to be applied, the dimensions of the image should be the same. The dimensions of the CT images used in this study are $512 \times 512$, while the dimensions of the MR images are $320 \times 260$. First of all, the frames were determined to include the object (Figure 4). Then, both CT and MR images were then rescaled to $512 \times 512$ (Figure 5). In this way, the images are made suitable for the fusion process.

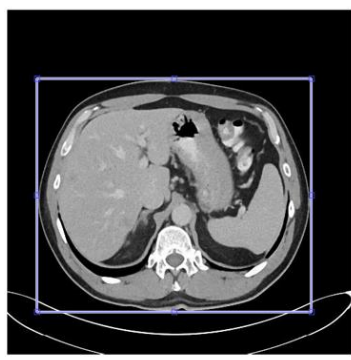

(a)

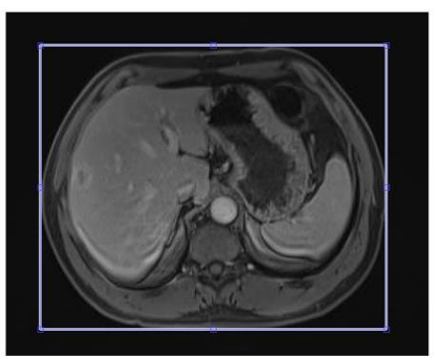

(b)
Figure 4. Frame determination process for image fusion (a) CT image (b) MR image

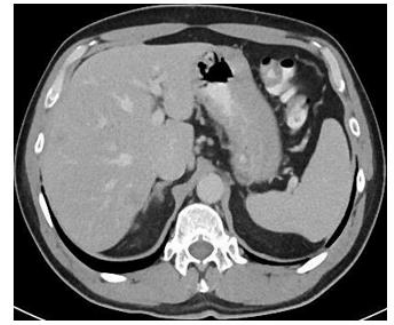

(a)

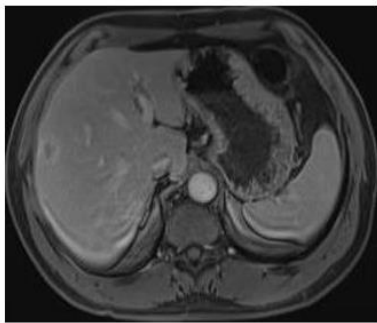

(b)
Figure 5. Resized $512 x 512$ images (a) CT image (b) MR image

\subsection{Image Fusion and Fusion Rules}

Image fusion is defined as the collection of important features from more than one image, combining them into fewer images, usually a single image (Cihan and Ceylan, 2021). This single image is more informative than any single source image and contains all the necessary information. In computer vision, image fusion is the process of combining relevant information from two or more images into a single image. The resulting image will have more information than any of the input images (Pjares and De La Cruz, 2004).

In this study, we use multiresolution analysis methods to combine CT and MR liver images. The principle of image fusion using multiresolution analysis methods is to combine the decomposition of images using fusion methods applied to approximation coefficients and detail coefficients.

Three different fusion rules were used for this study. In Equation 5-7, $\mathrm{C}$ and $\mathrm{M}$ letters denote the transform coefficients obtained from the images of the CT and MR, respectively. These rules were applied to each value of the coefficient matrices and at the end of the fusion process, combined images were obtained. Hence, all the features of CT and MR liver images are accumulated in one matrix. An example of DWT based fusion method is given in Figure 6.

$$
\begin{aligned}
& F 1=(C+M) / 2 \\
& F 2=\max (C, M) \\
& F 3=\min (C, M)
\end{aligned}
$$




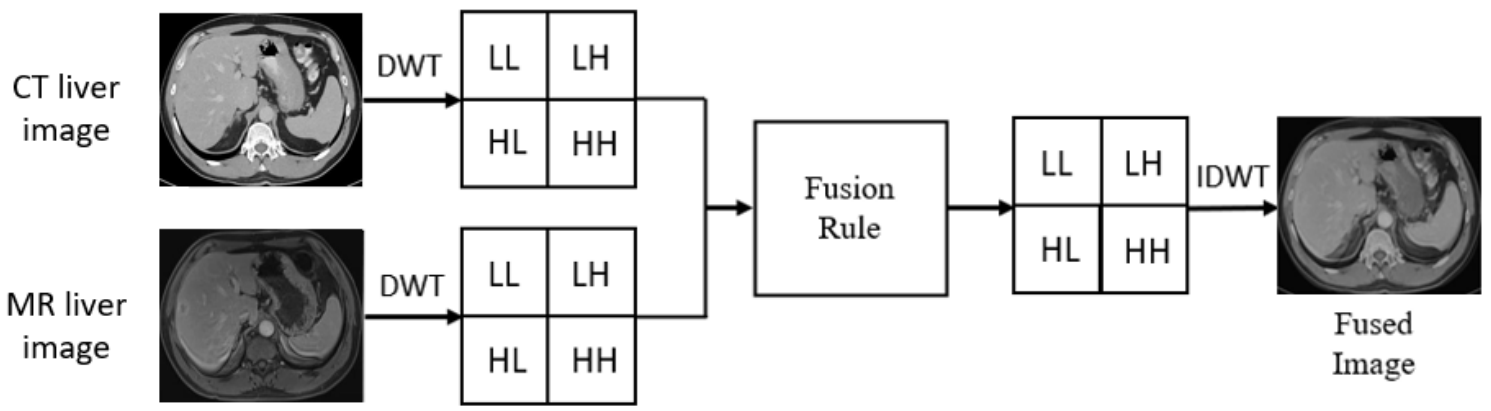

Figure 6. An example of 2D-DWT based fusion method

\subsection{Performance Measurement}

For the evaluation of the performance of the fusion algorithms, the visual quality of the obtained fusion result as well as the quantitative analysis are used. In order to compare the performances of Multiresolution Analysis methods, we have calculated PSNR, SSIM and MSE values for each image.

\subsubsection{Peak Signal to Noise Ratio (PSNR)}

PSNR is an objective performance test that provides scoring of loss information in $\mathrm{dB}$. Higher PSNR means less distortion (Chen et al., 2020). Given that $\mathrm{x}$ is the original image, $\mathrm{y}$ is the resulting image, $\sigma$ is standard deviation and $\mathrm{E}$ is error, the PSNR is represented as:

$\operatorname{PSNR}(x, y)=20 \cdot \log \left(\frac{255}{\sigma\left(\sum_{i}^{M} \sum_{j=1}^{N}\left(E_{x(i, j)}-E_{y(i, j)}\right)\right.}\right)$

\subsubsection{Structural Similarity Index Measure (SSIM)}

The SSIM index is calculated on various windows of an image. The measure between two windows $\mathrm{x}$ and $\mathrm{y}$ of common size $N x N$, let $\mu_{x}$ denote the mean of $\mathrm{x}$, let $\sigma_{x}^{2}$ and $\sigma_{x y}$ be the variance of $x$ and covariance of $x$ and $y$. The SSIM index between signals $\mathrm{x}$ and $\mathrm{y}$ is:

$$
\operatorname{SSIM}(x, y)=\frac{\left(2 \mu_{x} \mu_{y}+c_{1}\right)\left(2 \sigma_{x y}+c_{2}\right)}{\left(\mu_{x}^{2} \mu_{y}^{2} c_{1}\right)\left(\sigma_{x}^{2} \sigma_{y}^{2} c_{2}\right)}
$$

\subsubsection{Mean Square Error (MSE)}

MSE calculates the square of the numerical difference between two images. Low MSE means cleaner image. $\mathrm{R}$ and $\mathrm{C}$ specify the number of rows and columns of $\mathrm{x}$ and $\mathrm{y}$ images, while MSE is represented as:

$\operatorname{MSE}(x, y)=\frac{1}{R C} \sum_{i=1}^{R} \sum_{j=1}^{C}\left(x_{i, j}-y_{i, j}\right)^{2}$

\section{Experimental Results}

In this study, CT and MR liver images of 46 patients were used. The size of CT images is $512 \times 512$ while the size of MR images is $320 \times 260$. First of all, the frame detection process was applied to all the images to identify the objects, then all the images were resized and set to $512 \times 512$. The images were then fused using multiple resolution analysis methods. Three different fusion rules were applied to the transform coefficients for the image fusion. The obtained results after the fusion process are shown in Table 1 . The results in this table show the metrics obtained by averaging 46 images.

Table 1. Average values obtained as a result of the comparison of CT and MR images and fusion images

\begin{tabular}{|c|c|c|c|c|c|c|c|c|}
\hline \multirow{2}{*}{ Method } & \multirow{2}{*}{ Level } & \multirow{2}{*}{$\begin{array}{l}\text { Fusion } \\
\text { Rule }\end{array}$} & \multicolumn{2}{|c|}{ PSNR } & \multicolumn{2}{|c|}{ SSIM } & \multicolumn{2}{|c|}{ MSE } \\
\hline & & & $C T$ & $M R$ & $C T$ & $M R$ & $C T$ & $M R$ \\
\hline $2 D-D W T$ & 1 & F1 & 18,36949 & 18,36949 & 0,527214 & 0,380043 & 1395,262 & 1395,262 \\
\hline $2 D-D W T$ & 1 & F2 & 23,10355 & 13,93919 & 0,638749 & 0,304915 & 477,1125 & 5103,885 \\
\hline $2 D-D W T$ & 1 & F3 & 13,93919 & 23,10355 & 0,301645 & 0,446068 & 5103,885 & 477,1125 \\
\hline $2 D-D W T$ & 2 & F1 & 17,60758 & 18,24109 & 0,352820 & 0,306864 & 1594,978 & 1403,566 \\
\hline $2 D-D W T$ & 2 & F2 & 20,11053 & 13,94932 & 0,393808 & 0,228105 & 761,2442 & 5009,161 \\
\hline $2 D-D W T$ & 2 & F3 & 13,83836 & 22,28227 & 0,221411 & 0,276082 & 5168,845 & 538,1030 \\
\hline $2 D-D W T$ & 3 & F1 & 17,60758 & 18,24109 & 0,352820 & 0,306864 & 1594,978 & 1403,566 \\
\hline $2 D-D W T$ & 3 & F2 & 19,69203 & 13,99068 & 0,316629 & 0,199727 & 812,1168 & 4915,317 \\
\hline $2 D-D W T$ & 3 & F3 & 13,82199 & 21,24334 & 0,209998 & 0,187537 & 5108,327 & 622,3015 \\
\hline Ridgelet Transform & 2 & F1 & 18,36661 & 18,37218 & 0,526029 & 0,347978 & 1398,751 & 1391,825 \\
\hline Ridgelet Transform & 2 & F2 & 25,17167 & 13,44431 & 0,495610 & 0,125591 & 288,1630 & 4800,115 \\
\hline Ridgelet Transform & 2 & $\mathrm{~F} 3$ & 13,44114 & 25,17754 & 0,291788 & 0,284972 & 4813,979 & 288,1630 \\
\hline Real-valued Curvelet Transform & 2 & F1 & 18,36949 & 18,36949 & 0,527214 & 0,380043 & 1395,262 & 1395,262 \\
\hline Real-valued Curvelet Transform & 2 & $\mathrm{~F} 2$ & 20,54739 & 14,83667 & 0,436613 & 0,196760 & 656,9169 & 4305,758 \\
\hline Real-valued Curvelet Transform & 2 & F3 & 14,83667 & 20,54739 & 0,339900 & 0,184770 & 4305,758 & 656,9169 \\
\hline Complex-valued Curvelet Transform & 2 & F1 & 18,36949 & 18,36949 & 0,527214 & 0,380043 & 1395,262 & 1395,262 \\
\hline Complex-valued Curvelet Transform & 2 & $\mathrm{~F} 2$ & 25,18737 & 13,40693 & 0,673143 & 0,165977 & 239,7910 & 5147,907 \\
\hline Complex-valued Curvelet Transform & 2 & F3 & 13,40693 & 25,18737 & 0,052486 & 0,516165 & 5147,907 & 239,8022 \\
\hline
\end{tabular}


When Table 1 was examined, close values were obtained for all methods and metrics when the F1 fusion rule was applied. The reason for this is to obtain images that are close to each other by applying average values to the transform coefficients. In addition, it is seen that the 2D-DWT method performs poorly even at different levels. By using the complex-valued curvelet transform method and the F2 fusion rule, the best results were obtained for CT images. Again, using the complex-valued curvelet transform method and the F3 fusion rule, the best results for MR images were obtained. Also, the good results were obtained using the ridgelet transform method, using the $\mathrm{F} 2$ fusion rule for $\mathrm{CT}$ and the F3 fusion rule for MR. Real-value curvelet transform also remained underperforming for all fusion rules. Figure 7 shows CT and MR liver images. The fused images created using these images with MRA methods and three different fusion rules are shown in Figure 8. When we look at Figure 8, it is seen that better results are obtained with ridgelet transform and complex-valued curvelet transform.
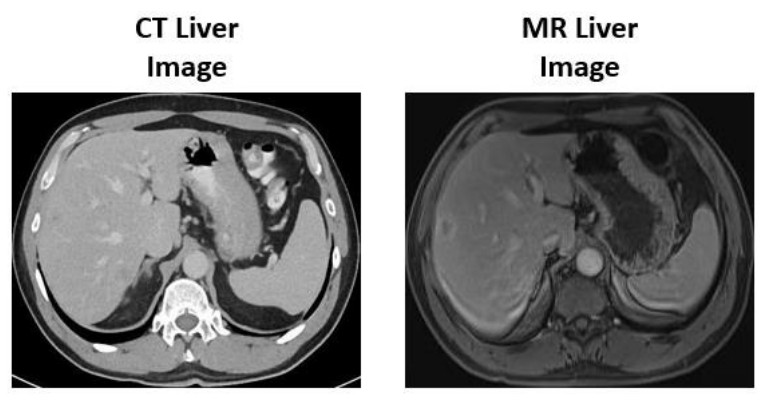

Figure 7. Example of CT and MR images
F1
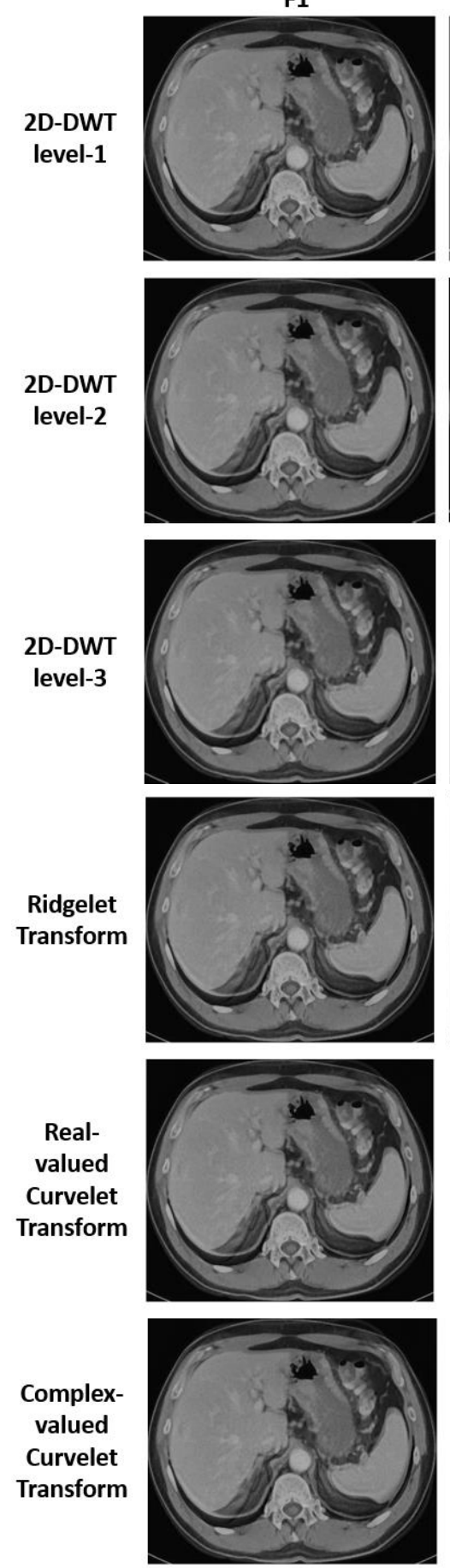

F2
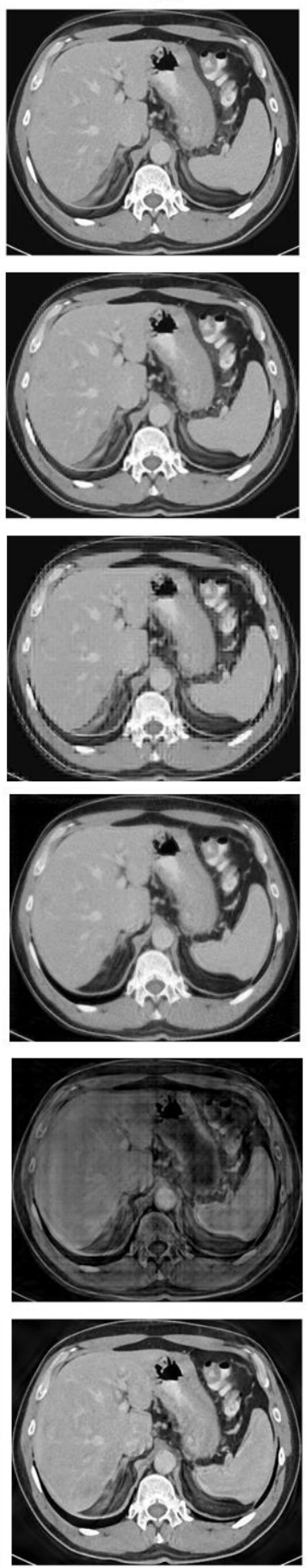

F3
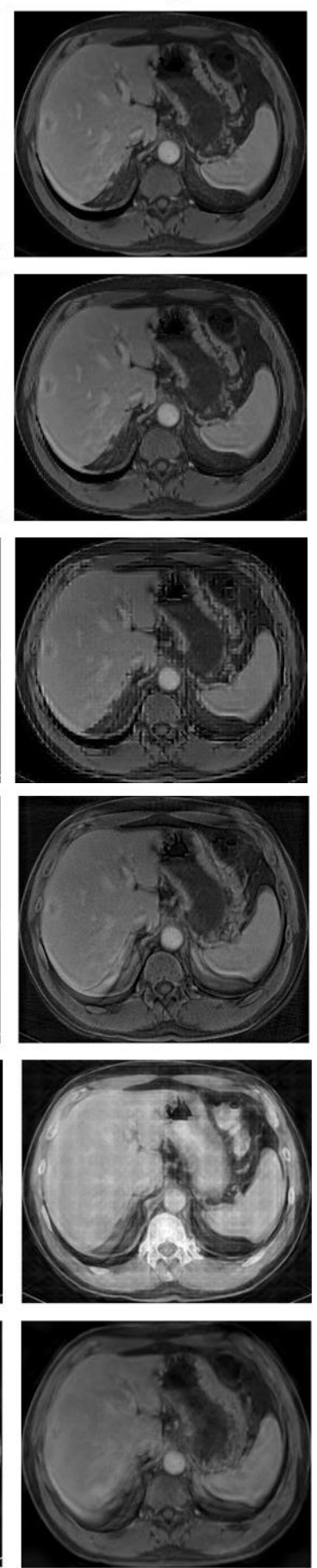

Figure 8. Fused images obtained for different MRA methods and fusion rules 


\section{Conclusion}

In this study, the ability of MultiResolution Analysis (MRA) methods in combining Computed Tomography (CT) and Magnetic Resonance (MR) liver images was compared. For the fusion process, 3 different (mean, maximum and minimum) fusion rules were applied to the transform coefficients. The images obtained as a result of fusion were compared using Peak Signal to Noise Rate (PSNR), Structural Similarity Index Measure (SSIM) and Mean Square Error (MSE) metrics. In addition, the images obtained as a result of fusion are shown in Figure 8, and these images are compared visually.

When the results were examined, the best results were obtained for both $\mathrm{CT}$ and MR images with complex-valued curvelet transform. While the maximum selection rule gave better results in $\mathrm{CT}$ images, the minimum selection rule gave better results in MR images. This is because the brightness in CT images is high, and the brightness in MR images is low. These results showed that complex-valued curvelet transform gives better results in $\mathrm{CT}$ and $\mathrm{MR}$ liver image fusion compared to other methods.

\section{References}

Ali, F. E., El-Dokany, I. M., Saad, A. A., \& Abd El-Samie, F. E. S. (2008). Curvelet fusion of MR and CT images. Progress in Electromagnetics Research, 3, 215-224.

Ali, F. E., El-Dokany, I. M., Saad, A. A., \& Abd El-Samie, F. E. (2010). A curvelet transform approach for the fusion of MR and CT images. Journal of Modern Optics, 57(4), 273-286.

Alzubi, S., Sharif, S., Islam, N. and Abbod, M. (2011). Multiresolution analysis using curvelet and wavelet transforms for medical imaging, IEEE International Workshop on Medical Measurements and Applications Proceedings, Bari-Italy, 188191.

Bhateja, V., Krishn, A., Patel, H., \& Sahu, A. (2015). Medical image fusion in wavelet and ridgelet domains: A comparative evaluation. International Journal of Rough Sets and Data Analysis (IJRSDA), 2(2), 78-91.

Candes, E. and Donoho, D.L. (1999). Ridgelets: the key to highdimensional intermittency, Philosophical Transactions of the Royal Society of London, 357 (1760), 2495-2509.

Candes, E. J., \& Donoho, D. L. (2004). New tight frames of curvelets and optimal representations of objects with piecewise C2 singularities, Communications on Pure and Applied Mathematics: A Journal Issued by the Courant Institute of Mathematical Sciences, 57(2), 219-266.

Candes, E.J., Demanet, L., Donoho, D.L. and Ying, L. (2006). Fast discrete curvelet transforms, Multiscale Modeling and Simulation, 5 (3), 861-899.

Chen, Y., Niu, K., Zeng, Z., \& Pan, Y. (2020). A wavelet based deep learning method for underwater image super resolution reconstruction, IEEE Access, 8, 117759-117769.

Cihan, M. and Ceylan, M. (2021). Fusion and CNN Based Classification of Liver Focal Lesions Using Magnetic Resonance Imaging Phases, Sigma Journal of Engineering and Natural Sciences, accepted.

Fadili, J. and Starck, J. L. (2009). Curvelets and ridgelets, R.A. Meyers, ed. Encyclopedia of Complexity and Systems Science, Springer New York, 1718-1738.

Mojsilovic, A., Popovic, M. and Sevic, D. (1996). Classification of the ultrasound liver images with the $2 \mathrm{~N} / \mathrm{spl}$ times/1-D wavelet transform, In Proceedings of 3rd IEEE International Conference on Image Processing, 1, 367-370.

Morlet, J., Arehs, G., Forugeau, I. and Giard, D. (1982). Wave Propogation and Sampling Theory, Geophysics, 47 (2), 203236.

Öztürk, A. E. and Ceylan, M. (2015). Fusion and ANN based classification of liver focal lesions using phases in magnetic resonance imaging, In 2015 IEEE 12th International Symposium on Biomedical Imaging (ISBI), 415-419.

Öztürk, A.E., Ceylan, M. and Kivrak, A.S. (2014). A new approach for liver classification using ridgelet / ripplet-II transforms, feature groups and ANN, 6th European Conference of the International Federation for Medical and Biological Engineering-MBEC 2014, Dubrovnik-Crotia, 130-133.

Pajares, G., \& De La Cruz, J. M. (2004). A wavelet-based image fusion tutorial. Pattern recognition, 37(9), 1855-1872. 